\title{
D.N. Thomas, G.E. Fogg, P. Convey, C.H. Fritsen, J.-M. Gili, R. Gradinger, J. Laybourn-Parry, K. Reid, and D.W.H. Walton (eds): The biology of polar regions
}

\author{
Oxford University Press, Oxford, 2008, \$130, 416 pp
}

\author{
Paul K. Dayton
}

Published online: 13 June 2010

(C) The Author(s) 2010. This article is published with open access at Springerlink.com

Many consider polar areas as little studied and pristine. Both assumptions are wrong, and this book considers a vast amount of scientific information and reviews only some of the enormous ongoing and future environmental changes resulting from human impacts. This book is one of the valuable Oxford Press Biology of Habitats series covering some dozen habitats. To give an idea of the scope of The Biology of Polar Regions, the authors have covered almost all the habitats in the rest of the series because polar habitats include a remarkably diverse array of marine, freshwater, and terrestrial habitats and the book reviews them all. Considering this scope, the book is a remarkable tour de force. Each chapter tackles materials that can and do fill entire books. As in most multi-author books, some authors have much broader perspectives than others, and to a certain extent the book is Eurocentric, reflecting areas of active research.

All habitats are bounded by a diverse group of abiotic factors, and these are especially important in polar areas; thus, it is appropriate that the first two chapters review some of the physical drivers and adaptations to these extreme ecosystems. These general chapters serve as a good introduction to the rest of the chapters that include the specific physical factors particularly important to each of the habitats.

All the terrestrial ecosystems including glacial habitats are covered in two chapters only. Considering the amount of the earth's surface these two chapters are remarkably complete and up to date reviews. Given the large difference between the Antarctic and Arctic terrestrial systems,

P. K. Dayton ( $\square)$

Scripps Institution of Oceanography, La Jolla, CA, USA

e-mail: pdayton@ucsd.edu chapter 3 has a particularly valuable comparison. Chapter 5 is a short chapter on freshwater lakes that covers the fascinating Antarctic systems in detail. Given the melting permafrost and extremely diverse Arctic freshwater systems vital to so many species of fish and birds, I was disappointed that the Arctic systems did not receive adequate coverage comparable to the Antarctic ones.

There are three marine chapters dedicated to open oceans, frozen oceans, and benthic habitats. Polar seas cover large and very important areas of the earth and deserve careful attention. The breakdown of these chapters understandably reflects the author's expertise; however, the total ocean ecosystems in both polar area integrates all three habitats in different ways and a synthesis might have been easier had each of the open water, ice, and benthic components of the Arctic and Antarctic seas been integrated in the chapters. That is, the Arctic marine ecosystem is dominated by large shallow shelves, continuous disturbance (both physical and anthropogenic), massive runoff replete with nutrients, organic material and pollutants, and the thick permanent ice has largely disappeared with the loss of important ice habitat structure. Most of these parameters are very different in the Antarctic and a holistic integration and comparison would have been interesting but probably beyond any reasonable scope of the book. These concerns are very carefully covered in each separate chapter as the authors having made the decision to consider the three main habitats as chapters have done a good job of comparing and integrating the bipolar patterns. I thought that the benthic chapter was particularly well done considering the differences between the two poles. Finally, a very interesting chapter covers the charismatic birds and mammals. This chapter does an excellent job synthesizing the different roles of the ice and open ocean systems in each polar ecosystem. 
One of the great strengths of the book is that the authors have not forgotten the important history, both geological and human, and this theme is especially apparent in the last two chapters. The climate change chapter starts with the recent Pleistocene and does a fine job reviewing the ice ages in the Arctic with their important biological changes. The history of refugia and cycles of colonization are important to our understanding of the massive changes that loom in our immediate future. I was impressed with the fact that the chapter was able to shift from the Arctic to the very different Antarctic systems and even included for both poles the different and interesting benthic marine systems. The climate changes are moving faster than most realize; one example since the book went to press and the time I write this review in early 2010 we know more about the almost complete loss of the important old ice in the Arctic Sea as well as the calving off of huge Antarctic ice shelves.

The sad long impact of humans on both polar ecosystems is nicely presented in the final chapter. In the Arctic, it seems clear that as the sea level rose and flooded the shelves, local people began to exploit marine mammals. This history is documented to at least 6,000 years in Alaska including the Old Whaling Culture that apparently killed whales on both sides of the Chukchi Sea some 4,000 years ago. Chapter 11 does an excellent job reviewing this history with a focus on the huge human impacts of recent times. Many of these impacts are probably irreversible, and this is an important chapter for the general public. In the south, one can only lament at the ease with which national commercial interests have perverted the ecosystem and precautionary ideals of CCAMLR.

This book should be read by college students as well as by professionals. Polar biologists will be impressed with the reviews of their own specialties and will profit from reading all the chapters.

Open Access This article is distributed under the terms of the Creative Commons Attribution Noncommercial License which permits any noncommercial use, distribution, and reproduction in any medium, provided the original author(s) and source are credited. 